the history by applying do-it-yourself methods to the data. There are many possible strands on offer for this historical weaving exercise, but clearly one of the most obvious candidates for choice is the one labelled 'logic'.

Several of the non-technical books whose recent appearance has coincided with the new 'interesting-and-respectable' period for artificial intelligence are written by philosophers, and make gestures towards logic only on the way towards concentration on philosophical issues. While Vernon Pratt is also trained in philosophy his interest here is more in tracing the sources of modern ideas about representation of knowledge and mathematical abstraction, and in particular their effects on the work of three heroes of computation: Leibniz, Babbage and Turing.

In passing, the book contains many other historical morsels from which the reader can make a do-it-yourself selection. It is less of a history of either computation or the evolution of artificial intelligence (for example, the links between the past and the post-1955 highlights in artificial intelligence are rather tenuous here) than a collection of information that establishes some of the intellectual climate in which the evolution has taken place. However, it gives an excellent summary account of the historical interplay of mathematical abstraction and the aims and expressiveness of mathematical logics, especially where this interplay has led to implicit assumptions about what 'logical' knowledge is and about how it can be represented. Because of this, it is useful reading even for those who are specialists in artificial intelligence, who may learn from it to take fewer of the classical assumptions behind knowledge-based computing for granted.

It may be ironic that this book has appeared at a time when the specialists have already begun to question whether the orthodox view, that knowledge-based computing is always reducible to symbolic and logical operations, is the only sensible view to take. The recent expansion of interest in connectionist computing and neural-net architectures is one consequence of the questioning. Artificial intelligence has a habit (already demonstrated for psychology and linguistics, among other areas) of overturning or at least disturbing the standard outlooks in subjects with which it comes in contact. There is no reason to suppose that mathematical logic will be immune to this process. Some of the pre-Cartesian ideas that receive brief mentions in Pratt's first chapters may not be dead and buried yet.

John A. Campbell is Professor of Computer Science at University College London, Gower Street, London WCIE 6BT, UK.

\section{Gaps in progress}

\section{David Brown}

Synaptic Function. Edited by Gerald M. Edelman, W. Einar Gall and W. Maxwell Cowan. Wiley:1987. Pp.789. Hbk \$149.95, £130; pbk\$39.95, £34.50.

ON receiving this book, my first thought was that it might be the ultimate text on synapses, able to reach those parts where other texts of general neuroscience could not penetrate. A closer look revealed that this is not the case: the book does not really achieve the status of a comprehensive treatise, but instead consists of a series of individual essays on various aspects of synaptic (and even non-synaptic) function. As a result, some parts of the subject are covered in detail but others are hardly touched upon.

The essays are grouped under five general headings: "Presynaptic and Postsynaptic Mechanisms"; "Neurotransmitters and Synaptic Function"; Synapses in Networks"; "Synaptic Plasticity, Memory, and Learning"; and "Theoretical Models of Synaptic Function". These subdivisions seem somewhat arbitrary, and there are a number of outriders and omissions. For example, in the first section there are three articles on the release of chemical transmitters (Llinas, Magleby, Korn \& Faber) yet none at all on their postsynaptic action; instead, the balance is made up by an article on gap junctions (Bennett \& Spray), and two articles on voltage-gated channels (Catterall, Hille) which seem misplaced here. Indeed, there is surprisingly little specific discussion of postsynaptic transmitter mechanisms in the book as a whole; even in Section 2, on neurotransmitters, the topic is restricted to one article on GABAactivated channels (Olsen), though some discussion of serotonergic and nicotinic mechanisms is incorporated in articles on learning by Kandel and Changeux, respectively, in the section on synaptic plasticity.

The individual essays vary considerably both in length (from 15 to 60 pages) and in format; some are research summaries, others are more generalized and speculative expositions. The former suffer from two disadvantages: in several cases (for example, co-transmission, $\mathrm{Na}$ and $\mathrm{Ca}$ channels, GABA receptors, learning in Aplysia, protein phosphorylation) similar ground has been covered in other such assemblies of articles; and these contributions are squeezed by the twin pincers of rapid progress and slow publication. Thus, there are very few references later than 1985, and I'm afraid this shows. For example, the chapter on learning-related phenomena in the hippocampus antedates recent knowledge regarding the permeability of NMDA-activated channels to $\mathrm{Ca}$, which would have facilitated the author's interpretation of LTP. Even more limiting is the fact that the article on molecular properties of $\mathrm{Na}$ and $\mathrm{Ca}$ channels was apparently completed before the amino acid sequence of the $\mathrm{Na}$ channel was described, a problem further exacerbated by the more recent cloning of the dihydropyridine-binding component of the $\mathrm{Ca}$ channel. For such reasons the longterm impact of this book is more likely to be determined by the more integrative and speculative articles, such as those on probabilistic release mechanisms (Korn \& Forber), dendritic function (Rall), computations (Koch \& Poggio) and population rules (Finkel \& Edelman).

In placing the book in context, it is worth noting that it is a publication of The Neurosciences Institute of the Neuroscience Research Program (NRP). In their original form, as published at threemonthly intervals (or thereabouts), the NRP Bulletins provided unique surveys of specific neuroscience topics which had the advantages of being focused, up-to-date and sufficiently cheap for the individual scientist to subscribe. These were progressively transmuted, firstly into the Study Programs which appeared at approximately three-year intervals, and then into the present reports of annual symposia of which this is the third, now published by Wiley and no longer particularly cheap. As a result, they have lost their unique place in neuroscience literature and have to compete with the myriad other symposial outpourings.

As such this volume is certainly worth having around because the author list is impressive and virtually every neuroscientist will find something of interest in it. Nevertheless, I personally miss the oldstyle NRP Bulletins; and the neuroscience world still awaits the definitive comprehensive treatise on synaptic function.

David Brown is a Professor in the Department of Pharmacology, University College London, Gower Street, London WC1E 6BT, UK, and Director of the MRC Neuropharmacology Research Group.

\section{New editions}

- Immunochemistry in Practice by Alan Johnstone and Robin Thorpe. Publisher is Blackwell Scientific, price is $£ 12.50, \$ 29.95$. For review see Nature 301, 182 (1983).

- Culture of Animal Cells by R. Ian Freshney. Publisher is Alan R. Liss, price is $\$ 59.50$. Available in the UK through Wiley, price $£ 45.50$. For review see Nature 307, 574 (1984).

- Five Kingdoms: An Illustrated Guide to the Phyla of Life on Earth by Lynn Margulis and Karlene V. Schwartz. Publisher is W.H. Freeman, price is hbk $£ 32.50, \$ 35.95$; pbk $£ 21.95$, $\$ 24.95$.

- Cancer Biology by R.W. Ruddon. Publisher is Oxford University Press, price is $£ 25, \$ 29.50$. For review see Nature 297, 714 (1982). 